\title{
Nucleosome assembly and epigenetic inheritance
}

\author{
Mo $\mathrm{Xu}^{1,2}$, Bing $\mathrm{Zhu}^{2} \bowtie$ \\ ${ }^{1}$ Graduate Program, Peking Union Medical College and Chinese Academy of Medical Sciences, Beijing 100730, China \\ ${ }^{2}$ National Institute of Biological Sciences, Beijing 102206, China \\ $\bowtie$ Correspondence: zhubing@nibs.ac.cn
}

Received August 5, 2010 Accepted August 16, 2010

\begin{abstract}
In eukaryotic cells, histones are packaged into octameric core particles with DNA wrapping around to form nucleosomes, which are the basic units of chromatin (Kornberg and Thomas, 1974). Multicellular organisms utilise chromatin marks to translate one single genome into hundreds of epigenomes for their corresponding cell types. Inheritance of epigenetic status is critical for the maintenance of gene expression profile during mitotic cell divisions (Allis et al., 2006). During S phase, canonical histones are deposited onto DNA in a replication-coupled manner (Allis et al., 2006). To understand how dividing cells overcome the dilution of epigenetic marks after chromatin duplication, DNA replication coupled (RC) nucleosome assembly has been of great interest. In this review, we focus on the potential influence of RC nucleosome assembly processes on the maintenance of epigenetic status.
\end{abstract}

KEYWORDS nucleosome assembly, epigenetic inheritance, DNA replication coupled

\section{INTRODUCTION}

An adult animal contains over 200 different cell types, each of them has specialized structure and distinct physiological function (Allis et al., 2006). With a few exceptions, all of these cells carry the same genetic information encoded by DNA. The identity of a given cell type is determined by its characteristic gene expression profile. During development and adult homeostasis, it is important to faithfully maintain this state after each cell division. Any unscheduled compromise might lead to developmental disorder or disease. Developmental studies in Drosophila in 1960s and 1970s demonstrated that cells can memorize their committed fates, even after being removed from their original environment and being cultured for several cell divisions (Hadorn, 1968; Eissenberg, 2006). For example, imaginal disc cells from Drosophila larvae can be cultured in vitro and undergo cell proliferation without differentiation. Moreover, these cultured cells can be transplanted back into larvae and differentiate into appropriate structures (Hadorn, 1968). This suggests that cells can remember their identity and transmit this information to the daughter cells during cell division. However, the underlying mechanism remains poorly understood.

Each nucleosome contains $146 \mathrm{bp}$ of DNA wrapping in 1.75 left-handed superhelical turns around a histone octamer (Luger et al., 1997). Histone octamer is organized with a central $\mathrm{H} 3 / \mathrm{H} 4$ tetramer flanked by two $\mathrm{H} 2 \mathrm{~A} / \mathrm{H} 2 \mathrm{~B}$ dimers at either side. Histone $\mathrm{N}$ - and $\mathrm{C}$-terminal tails protrude out of the DNA-protein globular core, which enable their modification sites to be accessible to a series of chromatin regulators (Luger et al., 1997). Long before understanding the subtlety of chromatin modifications, it was already proposed that chromatin structure could impact transcription (Allfrey and Mirsky, 1964). Thus potentially, chromatin modifications have regulatory roles in tissue specific gene expression (Paul and Gilmour, 1968). However, the direct connection between chromatin modification and transcriptional regulation was not established until the milestone discovery that characterized Tetrahymena homologue of yeast transcriptional regulatory protein Gcn5 as a histone acetyltransferase (Brownell et al., 1996). Since then, molecular mechanism underlying epigenetic control of chromatin structure was explosively unveiled (reviewed in Henikoff et al., 2004; Shilatifard, 2006; 
Shahbazian and Grunstein, 2007; Mosammaparast and Shi, 2010). Briefly, DNA is covalently modified by methylation on cytosine; histones are also post-translationally modified by acetylation, methylation, phosphorylation and ubiquitination, these modifications work in concert as a "histone code", which can be deciphered by a variety of modification binding proteins (Jenuwein and Allis, 2001); on the other hand, exchange of histone variants independent of DNA replication provides another layer of epigenetic regulation (Henikoff et al., 2004). Now, it is generally accepted that these epigenetic marks are necessary for the maintenance of chromatin signatures, including those regulating gene expression pattern (Polycomb silencing, position effect variegation and genomic imprinting, etc.), and those maintaining essential chromatin architectures such as centromere and telomere.

Since maintenance of epigenetic information is crucial for cell fate restriction during development, epigenetic marks are required to be appropriately transmitted from generation to generation during mitotic divisions. In mitotic cell cycle, DNA replication during $S$ phase poses an important question of how, once duplicated, epigenetic signatures are re-established on nascent chromatin. As a result of DNA polymerase passage, the structure of paternal nucleosomes (for example, the intra- and inter-nucleosome combination of histone modifications) is disrupted; old histones should be reorganized on newly synthesized DNA. At the same time, canonical histones are produced tightly coupling to DNA synthesis (Marzluff et al., 2008), fulfilling the gaps among parental histones. Therefore, pre-existing marks are diluted due to incorporation of new histones. In order to make the chromatin marks inheritable, organisms should evolve a refined mechanism to coordinate the recycling of paternal histones and the deposition of newly synthesized histones.

In this review, we will discuss the role of replication coupled chromatin assembly in restoration of epigenetic states, as well as the potential ways in which chromatin assembly can contribute to the inheritance of epigenetic marks.

\section{EARLY INVESTIGATIONS ON RC NUCLEOSOME ASSEMBLY AND THEIR CONTRIBUTIONS TO UNDERSTANDING OF EPIGENETIC INHERITANCE}

Early investigations on the fate of histones during $\mathrm{RC}$ nucleosome assembly addressed three questions that are fundamentally important to current concepts of epigenetic inheritance. (1) When disassembled from pre-replicative nucleosomes, parental histones, especially $(\mathrm{H} 3 / \mathrm{H} 4)_{2}$ tetramers, remain associated with DNA and they rapidly reassemble into nucleosomes on replicated DNA. (2) Pre-existing histones are randomly distributed to both of the nascent DNA strands in cluster. (3) The majority of parental $(\mathrm{H} 3 / \mathrm{H} 4)_{2}$ tetramers remain intact during DNA replication.

\section{$(\mathrm{H} 3 / \mathrm{H} 4)_{2}$ tetramers associate with DNA during replication fork passage}

As six major lysine methylation sites are present on either $\mathrm{H} 3$ (Lys4/9/27/36/79) or H4 (Lys20), mechanism that restricts massive exchanges between parental $\mathrm{H} 3 / \mathrm{H} 4$ and free histones during replication is vitally important to epigenetic inheritance, as it protects the existing chromatin modification pattern from disruption. It took many laboratories a decade starting from the mid 1980 s to address this question. The earliest clue came from experiments using the SV40 minichromosome replication system. Using electron microscopy to study psoralen cross-linked replicating SV40 chromatin, Sogo et al. found that replication fork moves up to, and possibly penetrates into, the unreplicated parental nucleosome ahead; nascent nucleosomes assembled on the replicated DNA at distances of $225 \mathrm{bp}$ and $285 \mathrm{bp}$ from the branching point separately for the leading and lagging strands (Sogo et al., 1986). This suggests that a full set of core histones are rapidly reassembled following replication advancement. The first direct evidence for the association of parental histones with replicating DNA was obtained using a defined prokaryotic chromatin replication system. Chromatin were assembled with purified core histones and plasmid DNA, and then replicated by replication proteins purified from bacteriophage T4. Core histones reassemble on replicated DNA even in the presence of excessive nucleosome-free competitor DNA (Bonne-Andrea et al., 1990). This was further confirmed with the SV40 minichromosomes isolated from lytically infected cultured cells (Krude and Knippers, 1991; Sugasawa et al., 1992) or in vitro assembled chromatin containing SV40 replication origin (Randall and Kelly, 1992). These studies also postulated that the pre-existing histones remain bound during the replication process. However, contradictions remain: Sugasawa et al. (1992) and Randall et al. (1992) concluded that old octamers do not dissociate from replicating DNA. However, the ratio of competitor DNA to chromatin DNA (0.3-1) in these experiments was low. In contrast, data from some other groups suggest the parental octameric structures are disrupted during the passage of replication fork (Sogo et al., 1986; Fotedar and Roberts, 1989), and some $\mathrm{H} 2 \mathrm{~A} / \mathrm{H} 2 \mathrm{~B}$ dimers dissociate from replicating DNA (Jackson, 1987, 1990). Finally, using an improved in vitro replication method, Gruss et al. clarified the debate and provided further insights (Gruss et al., 1993). The authors concluded that, a subnucleosomal particle, probably the $(\mathrm{H} 3 / \mathrm{H} 4)_{2}$ tetramer is the transfer unit, which, then assembled with two $\mathrm{H} 2 \mathrm{~A} / \mathrm{H} 2 \mathrm{~B}$ dimers to form an intact nucleosome. In addition, 5-10 folds of competitor DNA during replication traps histones transferred to daughter strands, suggests that the histones may only loosely associated with replicating DNA (Gruss et al., 1993). However, a few open questions remain, such as what are the chaperon factors that assist the disassembly/reassembly process of the parent nucleosomes 
and how they coordinate with chaperons facilitate the deposition of newly synthesized histones.

\section{Parental histones are randomly distributed to newly synthesized DNA}

In order to transmit the pre-existing marks to newly deposited histones, the establishment of modifications on new histones should be, at least to some extent, guided by pre-existing modifications on parental histones. Thus, the way in which parental histones are distributed to daughter DNA strands might determine the inheritability of histone marks. One early model proposed that the old histones cover the leading strand of the replication fork while newly synthesized histones complex with the lagging strand (Seale, 1976; Riley and Weintraub, 1979; Seidman et al., 1979). However, after a period of debate, the field has finally reached to the conclusion (McKnight and Miller, 1977; Cusick et al., 1981, 1984; Fowler et al., 1982; Pospelov et al., 1982; Annunziato and Seale, 1984; Jackson and Chalkley, 1985) that parental histones are randomly distributed to both leading and lagging strands. Most of the early studies on parental histone segregation were carried out in cycling cells with the treatment of protein synthesis inhibitors, such as cycloheximide and puromycin. Subsequent experiments were based on nuclease digestion followed with electrophoresis or sedimentation (Pospelov et al., 1982; Annunziato and Seale, 1984; Jackson and Chalkley, 1985) or based on electron microscopy (McKnight and Miller, 1977) to analyze so called "cycloheximide chromatin". Taken together, these evidences demonstrated that parental histones are dispersively segregated to both copies of newly replicated DNA. The same question was also investigated in a cell free system for SV40 minichromosome replication (Cusick et al., 1984; Krude and Knippers, 1991; Randall and Kelly, 1992). In the absence of free histone supply, parental histones segregate to both of the nascent DNA strands, in consistence with the studies performed in living cells treated with protein synthesis inhibitors.

\section{$\mathrm{H} 3 / \mathrm{H} 4$ segregated to daughter strands as tetramers}

In the past three decades, large amount of literature can be found on the discussion: how pre-replicative $(\mathrm{H} 3 / \mathrm{H} 4)_{2}$ tetramers are segregated during replication. One model concluded that old $\mathrm{H} 3 / \mathrm{H} 4$ are transferred to nascent DNA as tetramers, in contrast, the other one proposed that parental $\mathrm{H} 3 / \mathrm{H} 4$ tetramers dissociate into dimers, then each old $\mathrm{H} 3 / \mathrm{H} 4$ dimer assembles with a newly synthesized $\mathrm{H} 3 / \mathrm{H} 4$ dimer. In recent years, the debate on this seemingly trivial issue attracted increasing attention for its potential significance in the inheritance of histone modifications (reviewed in Nakatani et al., 2004; Annunziato 2005; Henikoff and Ahmad, 2005; Hake and Allis, 2006; Groth et al., 2007; Martin and Zhang,
2007; Probst et al., 2009). If the $(\mathrm{H} 3 / \mathrm{H} 4)_{2}$ tetramer split model is correct, it provides a perfect model for the transmission of histone modifications, in which new $\mathrm{H} 3 / \mathrm{H} 4$ dimer could use the epigenetic information at the old $\mathrm{H} 3 / \mathrm{H} 4$ dimer within the same nucleosome as a template to precisely establish its modifications, thus faithfully restore the information of parental nucleosome at exactly the same genomic region. Historically, there are good evidences for the $\mathrm{H} 3 / \mathrm{H} 4$ tetramer non-split model. In 1980, using the slime mold Physarum as a model, Prior et al. (1980) examined the long term stability of $\mathrm{H} 3-\mathrm{H} 3$ interactions. Data showed that, even after five rounds of DNA replication, the original $\mathrm{H} 3-\mathrm{H} 3$ interaction can still be detected, indicating that $(\mathrm{H} 3 / \mathrm{H} 4)_{2}$ tetramers are stable during multiple cell generations in vivo (Prior et al., 1980). Ten years after this discovery, Jackson studied the fate of $(\mathrm{H} 3 / \mathrm{H} 4)_{2}$ tetramers in proliferating mammalian cultured cell via density labeling and sedimentation approach (Jackson, 1990). The author concluded that in contrast to the massive exchange of $\mathrm{H} 2 \mathrm{~A} / \mathrm{H} 2 \mathrm{~B}$ dimers, most $(\mathrm{H} 3 / \mathrm{H} 4)_{2}$ tetramers do not split even after several rounds of DNA replication. Yamasu and Senshu (1990) also studied the same question by dense labeling in a method different from Jackson's, which provided similar conclusion. Although most of these studies favored the $\mathrm{H} 3 / \mathrm{H} 4$ tetramer non split model, the recent discoveries found that $\mathrm{H} 3 / \mathrm{H} 4$ histones deposit into chromatin as dimers, rather than as tetramers (Tagami et al., 2004; English et al., 2005; Benson et al., 2006). Crystal data clearly showed the heterotrimeric structure of Asf1-H3/H4 (Natsume et al., 2007). In addition, Asf1 can disassemble the preformed $\mathrm{H} 3 / \mathrm{H} 4$ tetramers, thus potentially allowing the newly synthesized $\mathrm{H} 3 / \mathrm{H} 4$ dimers to be paired with old $\mathrm{H} 3 / \mathrm{H} 4$ dimers (Natsume et al., 2007). These results again raised the possibility of $\mathrm{H} 3 / \mathrm{H} 4$ tetramer split model and spurred the debates. We reinvestigated the question by selectively purifying mono-nucleosomes containing one "old" histone H3.1 and determined that its partner histone $\mathrm{H} 3.1$ is also an old one by stable isotope labeling based quantitative mass spectrometry ( $\mathrm{Xu}$ et al., 2010). This study was variant specific and distinguished the "old" and "new" histones with full resolution, thus effectively put the $\mathrm{H} 3 / \mathrm{H} 4$ tetramer splitting model to an end, at least for the canonical histones. Therefore, if there is any templated modification copying event, it could only occur by copying methylation marks from neighboring nucleosomes.

\section{MOLECULAR MECHANISM OF REPLICATION COUPLED CHROMATIN DISASSEMBLY AND REASSEMBLY}

Developmentally regulated gene expression is achieved by heritable changes in chromatin structure during cell differentiation. In higher organism, refined mechanisms are evolved both to change chromatin structure and to maintain these structures to daughter cells. DNA replication disrupts chromatin organization and dilutes epigenetic marks, thus 
provides a window of opportunity to implement these maintenances or changes between cell generations. Therefore, the molecular model underlying these processes is highly interesting. To address this question, the first priority is to understand how chromatin is assembled during DNA replication. Replication coupled chromatin duplication contains the process of chromatin disassembly ahead of replication fork and chromatin reorganization behind the fork. During replication fork progression, high order chromatin structure is destabilized in a stretch of approximately two nucleosomes in the parental chromatin (Gasser et al., 1996), and the first pre-replication nucleosome is disrupted (Sogo et al., 1986). The restoration of chromatin structure behind of replication fork can be divided into several steps. First, assembly begins with the incorporation of $\mathrm{H} 3 / \mathrm{H} 4$ tetramer, which is followed by the addition of two $\mathrm{H} 2 \mathrm{~A} / \mathrm{H} 2 \mathrm{~B}$ dimmers, to form a complete nucleosome structure (Jackson, 1987, 1990; Gruss et al., 1993). The incorporation of linker histone was detected 450-650 bp after replication fork passage (Gasser et al., 1996), enabling further folding of higher order structures. The molecular machinery involved in these processes will be discussed in the following section.

\section{Disassembly of chromatin structure ahead of replication fork}

Replication of eukaryotic genome requires various replication factors to be in close contact with DNA, it is hard to think all of these processes can occur in the nucleosome context. In a defined in vitro replication system, the disassembly of nucleosome can be achieved by the progression of replication fork itself (Sugasawa et al., 1992), either due to unwinding of DNA helix by MCM2-7 helicase complex or the moving of replication machinery. However, like many other chromatin based processes such as transcription and DNA repair, replication coupled nucleosome disassembly is believed to be facilitated by ATP dependent chromatin remodeling factors and histone chaperons in vivo.

Several ATP dependent chromatin remodeling complexes are thought to play important role in disassembly of prereplicative chromatin. ACF1-SNF2h was reported to be essential for the replication of heterochromatin in cultured mammalian cells (Collins et al., 2002). Other evidence showed that ISWI type nucleosome remodeling complex SNF2h is recruited to replication fork by WTSF, RNAi mediated knock down of SNF2h or WTSF caused reduction of DNA replication efficiency during $S$ phase (Poot et al., 2004). In S. cerevisia INO80 complex is enriched in replication origins and stalled replication forks under replicative stress (Papamichos-Chronakis and Peterson, 2008; Vincent et al., 2008). Furthermore, mutation of INO80 leads to loss of replisome proteins under replicative stress (Papamichos-Chronakis and Peterson, 2008).

Disassembly of pre-replicative nucleosome is thought to be accomplished by dissociation of $\mathrm{H} 2 \mathrm{~A} / \mathrm{H} 2 \mathrm{~B}$ dimmers from nucleosomes followed by the removal of $(\mathrm{H} 3 / \mathrm{H} 4)_{2}$ tetramers. Multiple histone chaperones are found to be involved in this process. FACT complex which contains SPT16 and SSRP1 in human and Spt16 and Pob3 in yeast was first isolated as a transcription elongation factor (LeRoy et al., 1998; Orphanides et al., 1998). It has histone chaperone activity to both $\mathrm{H} 2 \mathrm{~A} / \mathrm{H} 2 \mathrm{~B}$ and $\mathrm{H} 3 / \mathrm{H} 4$ (Belotserkovskaya et al., 2003; Stuwe et al., 2008), and replaces $\mathrm{H} 2 \mathrm{~A} / \mathrm{H} 2 \mathrm{~B}$ dimers from transcribing nucleosomes (Belotserkovskaya et al., 2003). In recent years, accumulating evidence showed that FACT also involves in chromatin replication. Using budding yeast as a model, VanDemark et al. (2006) showed FACT interacts with single strand binding protein RPA; Gambus et al. (2006) found FACT co-purifies with replication complex. These results were supported by genetic evidence that budding yeast FACT mutant is sensitive to replicative stress during hydroxyurea treatment (Schlesinger and Formosa, 2000). In mammals, FACT localizes to replication foci (Hertel et al., 1999; Tan et al., 2006) and interacts with MCM helicase (Tan et al., 2006). Another histone chaperone which potentially functions in removal of parental histones during replication is Asf1. Yeast Asf1 directly binds RFC in vitro, deletion of Asf1 results in reduced integrity of stalled replisome (Franco et al., 2005). In Drosophila S2 cells, Asf1 localizes to DNA replication foci during $S$ phase, RNAi knockdown of dASF1 leads to accumulation of cells in S phase (Schulz and Tyler, 2006). In human cells, Asf1 binds MCM helicase complex, through $\mathrm{H} 3$ and $\mathrm{H} 4$. In the absence of Asf1, the proliferating cells represent delayed $S$ phase progression and reduced DNA unwinding at replication fork (Groth et al., 2007). Furthermore, posttranslational modifications on chromatin were found in $\mathrm{H} 3$ co-purified with Asf1, suggests at least some of the $\mathrm{H} 3 / \mathrm{H} 4$ dimers bound to Asf1 were evicted from pre-fork nucleosomes (Groth et al., 2007; Jasencakova et al., 2010).

\section{Restoration of chromatin structure behind replication fork}

The histones assembled onto replicated DNA are half from parental histone evicted ahead of replication fork and half from the pool containing newly synthesized histones. Although there is much work describing how parental nucleosomes are disassembled during replication as discussed above, little is known about the proteins responsible for the transfer of old histones. It is partially because the same histone chaperone may participate in multiple processes, including disassembly of the parental nucleosomes, transfer of the old histones and packaging of the nascent chromatin. Loss of function studies were performed on histone chaperones might be involved in delivery of old histones to nascent chromatin such as FACT and Asf1, and stalled replication fork advancement were observed. However, we can not distinguish whether these results are the consequence of impaired 
nucleosome disassembly ahead of replication fork or impaired nucleosome reassembly behind the fork.

While our knowledge on histone chaperones related to the delivery of old histones is limited, the mechanism of depositing newly synthesized histone onto daughter DNA was extensively studied. Early attempts to uncover the molecular mechanism were carried out using in vitro replication of SV40 chromatin as a model. Efficient chromatin assembly on newly synthesized DNA requires the addition of nuclear factors. Smith et al. followed this RC nucleosome assembly activity in nuclear extract and isolated a three subunit protein complex termed as chromatin assembly factor I, CAF-I (Smith and Stillman, 1989). In cell free system, the loading of PCNA (proliferating cell nuclear antigen) is required for CAF-I mediated chromatin assembly (Shibahara and Stillman, 1999); furthermore, p150, the largest subunit of CAF-I complex directly interacts with PCNA (Shibahara and Stillman, 1999; Moggs et al., 2000). The interaction of p150 with histone $\mathrm{H} 3 / \mathrm{H} 4$ through its $\mathrm{KER}$ and $\mathrm{ED}$ domains demonstrates CAF-1's histone chaperone activity (Kaufman et al., 1995). Moreover, histone $\mathrm{H} 4$ co-purified with CAF-1 are acetylated on $\mathrm{K} 5$ and $\mathrm{K} 12$, suggests they are newly synthesized in the cytoplasm (Kaufman et al., 1995; Verreault et al., 1996). In vivo data from different model organisms supported the conclusion of above in vitro experiments. Both RNAi mediated knockdown and overexpression of a dominant negative CAF-1 in cultured human cells result in defective assembly of newly replicated chromatin (Hoek and Stillman, 2003; Ye et al., 2003; Nabatiyan and Krude, 2004). Conditional depletion of CAF-1 p150 or p60 subunit in chicken DT40 cells leads to delayed $S$ phase progression concomitant with slower DNA synthesis (Takami et al., 2007).

Acetylation appears to be a signature of newly synthesized histone $\mathrm{H} 3$ and $\mathrm{H} 4$. When synthesized in cytoplasm, $\mathrm{H} 4$ is acetylated at K5 and K12 (Sobel et al., 1995; Benson et al., 2006), these acetyl-groups are removed within 20 min after chromatin assembly (Taddei et al., 1999). In DT40 cells, HAT1 mediates $\mathrm{H} 4$ acetylation at these two sites (Barman et al., 2006). However, HAT1 is not required for replication coupled chromatin assembly in vivo (Barman et al., 2006). Thus, the role of $\mathrm{K} 5$ and $\mathrm{K} 12$ acetylation in nucleosome assembly remains to be uncovered. Newly synthesized $\mathrm{H} 3$ is acetylated at K56 in budding yeast (Masumoto et al., 2005) and mammals (Xie et al., 2009; Das et al., 2009). This modification is catalyzed by Rtt109 in budding yeast (Han et al., 2007; Tsubota et al., 2007), and requires the presence of histone chaperone Asf1 (Recht et al., 2006; Tsubota et al., 2007). H3 lysine 56 resides at the DNA entrance site in a nucleosome, the acetylation on this residue was reported to loosen the histone-DNA contact and increase nucleosome breathing (Neumann et al., 2009). Furthermore, H3K56ac serves a key role in RC nucleosome assembly. Li et al. (2008) found that acetylated $\mathrm{K} 56$ greatly increases the affinity of $\mathrm{H} 3$ to histone chaperone Rtt106 and CAF-1, thus promotes the nucleosome formation following DNA replication.

\section{THE ROLE OF REPLICATION COUPLED NUCLEOSOME ASSEMBLY IN CHROMATIN RESTORATION}

The biochemical characterization of factors involved in RC chromatin assembly offers an opportunity for genetically dissecting the relationship between nucleosome assembly and chromatin marking. Although the evidence is still limited, experiments based on RNA interference and knockout approaches in vivo provide some insights into the role of $\mathrm{RC}$ nucleosome assembly in epigenetic inheritance.

PCNA is an essential factor in DNA replication. It is loaded onto replicating DNA strand as heterotrimer in a ring like structure and then travels along with the replication fork. Yeast bearing mutant PCNA with reduced CAF1 interaction also displayed reduced gene silencing near telomere and silencing mating type loci, suggesting that PCNA participates in inheritance of not only DNA sequence but also epigenetic states (Zhang et al., 2000). To date, CAF-1 is the only known histone chaperone whose function is dedicated to the progression of DNA synthesis. Studies of CAF-1 in yeast led to the discovery of its role in the maintenance of silenced chromatin structures. Yeast strains bearing deletion mutations of CAF-1 subunits are viable, suggesting the role of CAF-1 in nucleosome assembly can be partially compensated by other pathways. However, these strains fail to maintain the repression states of distinct genome region such as telomere and mating type loci (Enomoto et al., 1997; Kaufman et al., 1997; Monson et al., 1997). Enomoto et al. provided further insight into the underlying mechanism using the yeast silent $\mathrm{HM}$ locus (HML) as a model (Enomoto and Berman, 1998), they found that CAF-1 is required for the maintenance of $\mathrm{HML}$ silencing during DNA replication, but not the re-establishment of silencing in alpha-factor arrested cells (Enomoto and Berman, 1998). Meijsing and EhrenhoferMurray (2001) discovered a genetic interaction between CAF-1 and yeast histone acetyltranferase SAS-1, which functions in promoting the silencing state on yeast telomere and mating type loci. This suggests that there might be some kind of connection between re-establishment of histone acetylation patterns and nucleosome assembly.

However, the heterochromatin structure in budding yeast is dramatically different from that of higher eukaryotes. Heterochromatin in higher organisms is much more complicated, with many additional components. Thus, whether nucleosome assembly is also important for maintaining epigenetic states in higher eukaryotes has attracted much attention. Temperature sensitive mutants of PCNA have been characterized in Drosophila, all of them strongly suppress PEV (position effect variegation), which reveals a role for insect 
PCNA in chromatin assembly and modification (Henderson et al., 1994). Unlike Drosophila and mammals, in which CAF-1 is essential for survival, plants harboring deletions of either FAS1 or FAS2 (Arabidopsis CAF-1 p150 and p60) are viable (Kaya et al., 2001). Interestingly, knockout of Arabidopsis FAS1 or FAS2 disrupts the integrity of cellular organization in shoot apical meristem and root apical meristem. Functional study suggests fas mutants fail to maintain the expression of some meristem specific genes essential for its identity (Kaya et al., 2001), suggesting a critical role for CAF-1 in maintaining gene expression profile in proliferating cells.

\section{THE POTENTIAL ROLE OF RC CHROMATIN ASSEMBLY IN EPIGENETIC INHERITANCE}

As discussed above, replication coupled chromatin assembly not only packages all the newly produce DNA into nucleosome structure, but also contribute to the inheritance of chromatin state. How can nucleosome assembly affect the restoration of chromatin marks? Two potential mechanisms on distinct spatial and temporal circumstances can be envisioned: (1) restoring epigenetic marks right behind the replication fork in a replication-coupled manner; (2) establishing chromatin modifications during chromatin maturation independent of DNA replication.

\section{Inheritance of epigenetic marks behind the replication fork?}

During S phase, PCNA is loaded onto replicating DNA to facilitate the progression of both leading and lagging strand DNA polymerases. In recent years, in addition to the role in DNA synthesis, PCNA was found to coordinate the process of DNA synthesis, nucleosome assembly and inheritance of epigenetic marks. PCNA directly interacts with a series of chromatin modifying enzymes, and potentially recruits them to replication foci. These factors include CAF-1 (Shibahara and Stillman 1999; Moggs et al., 2000), HDACs (Milutinovic et al., 2002), ATP dependent chromatin remodeling complex WSTF-SNF2h (Poot et al., 2004), histone lysine methyltransferse PR-SET7 (Jørgensen et al., 2007; Huen et al., 2008) and DNA methyltransferase DNMT1 (Leonhardt et al., 1992; Chuang et al., 1997). CAF-1 is also reported to interact with chromatin factors, including MBD1 (methyl CpG-binding protein 1) and SETDB1 during heterochromatin DNA replication (Reese et al., 2003; Sarraf and Stancheva, 2004). In addition, DNMT1 directly interacts with histone H3K9 methyltransferase G9a, and recruits G9a to the replication foci (Estève et al., 2006). Using high resolution imaging techniques, Taddei et al. (1999) provided evidences that CAF-1 persists on newly replicated DNA after its synthesis for a period of more than $20 \mathrm{~min}$, in consistence with the in vitro finding that CAF-1 assembles nucleosome post-replication
(Shibahara and Stillman, 1999). In addition, a similar phenomenon was also observed on PCNA by fluorescent bleaching experiment (Sporbert et al., 2002). Hence, the association of PCNA and CAF-1 on replicated DNA could present a time window for synergistic restoration of chromatin structure and epigenetic marks. An attractive hypothesis is that, after traveling along with replication fork for a certain distance, PCNA and CAF-1 dissociate from the replisome and retain on the patch of newly synthesized DNA, during this period, they can serve as a landing pad for those chromatin modifying factors. As a consequence, histone deacetylases, histone methyltransferses, DNMT1 and ATP dependent chromatin remodeling factors can be recruited to this stretch of nascent chromatin, and work in concert to restore the epigenetic states.

\section{Establishing chromatin modification during chromatin maturation independent of DNA replication?}

Recently, stable isotope labeling based quantitative mass spectrometry provided new insights into the modifying events on newly deposited histones. Studies comparing the level of PTMs on new and old histones during cell cycle progression showed that while acetylation marks are quickly installed on new histones, the establishment of several methylation marks appears to be much slower (Pesavento et al., 2008; Scharf et al., 2009). Another experiment investigating the turnover rate of histone methylation suggests it takes more than one cell cycle to establish some of the methylation patterns (Zee et al., 2010). Thus, the re-establishment of certain methylation marks may occur during chromatin maturation independent of DNA replication.

\section{Templated chromatin modification copying event?}

In order to be inheritable, a pre-existing mark should be able to serve as a template to guide its establishment on newly synthesized histones. Potential examples of such copying events have been described for two histone modifications, $\mathrm{H} 3 \mathrm{~K} 9 \mathrm{me} 3$ and H3K27me3. H3K9me3 at peri-centromeric heterochromatin is mainly catalyzed by histone methyltransferase SU(VAR)3-9 conserved from fission yeast (Clr4) to human (SU(VAR)3-9h1 and SU(VAR)3-9h2) (Rea et al., 2000; Nakayama et al., 2001; Peters et al., 2001). HP1 is a heterochromatin specific protein essential for maintenance of heterochromatin structure (Eissenberg et al., 1990). HP1 recognizes $\mathrm{H} 3 \mathrm{~K} 9 \mathrm{me} 3$ with its chromodomain (Bannister et al., 2001; Lachner et al., 2001). In addition, HP1 interacts with Suv39 with its chromoshadow domain (Stewart et al., 2005). Moreover, the heterchromatic localization of HP1 and Suv39 are interdependent (Schotta et al., 2002). Therefore, although the H3K9me3 is also regulated by other mechanisms, such as RNAi in fission yeast (Volpe et al., 2002) and DNA methylation in mammals (Espada et al., 2004), the 
positive feedback loop composed of Suv39 and HP1 does contribute to the recovery of its level after S phase. Another example is the self propagation of $\mathrm{H} 3 \mathrm{~K} 27 \mathrm{me} 3$, a mark catalyzed by polycomb group protein PRC2, which is known as a regulator of cell memory (Schwartz and Pirrotta, 2007). Recently, using a reporter system in cultured human cells, Hansen et al. (2008) showed that H3K27me3 mediated gene silencing, once established, can be maintained independent of genetic elements through several cell divisions. They also found an in vitro binding between PRC2 and $\mathrm{H} 3$ tail trimethylated on lysine 27 (Hansen et al., 2008), which provides a possible explanation for the in vivo self maintenance. Combining structural biology, biochemistry and Drosophila genetics, Margueron et al. (2009) showed the potential mechanism of $\mathrm{H} 3 \mathrm{~K} 27 \mathrm{me} 3$ transmission from mother cells to daughter cells. The PRC2 component EED binds H3K27me3, which results in the allosteric activation of PRC2 (Margueron et al., 2009). Moreover, Drosophila carrying EED mutations that are defective in binding H3K27me 3 has reduced $\mathrm{H} 3 \mathrm{~K} 27$ methylation level and a polycomb phenotype (Margueron et al., 2009).

\section{ACKNOWLEDGEMENTS}

This work was supported by the National Programs for High Technology Research and Development Program (863 Program) (Grant No. 2007AA02Z1A6, to B.Z.).

\section{REFERENCES}

Allfrey, V.G., and Mirsky, A.E. (1964). Structural modifications of histones and their possible role in the regulation of RNA synthesis. Science 144, 559.

Allis, C.D., Jenuwein, T., and Reinberg, D. (2006). Overviews and concepts. In Epigenetics, C.D. Allis, T. Jenuwein and D. Reinberg, ed. (New York, USA: Higher Education Press and SpringerVerlag). pp. 23-56.

Annunziato, A.T. (2005). Split decision: what happens to nucleosomes during DNA replication? J Biol Chem 280, 12065-12068.

Annunziato, A.T., and Seale, R.L. (1984). Presence of nucleosomes within irregularly cleaved fragments of newly replicated chromatin. Nucleic Acids Res 12, 6179-6196.

Bannister, A.J., Zegerman, P., Partridge, J.F., Miska, E.A., Thomas, J. O., Allshire, R.C., and Kouzarides, T. (2001). Selective recognition of methylated lysine 9 on histone H3 by the HP1 chromo domain. Nature 410, 120-124.

Barman, H.K., Takami, Y., Ono, T., Nishijima, H., Sanematsu, F., Shibahara, K., and Nakayama, T. (2006). Histone acetyltransferase 1 is dispensable for replication-coupled chromatin assembly but contributes to recover DNA damages created following replication blockage in vertebrate cells. Biochem Biophys Res Commun 345, 1547-1557.

Belotserkovskaya, R., Oh, S., Bondarenko, V.A., Orphanides, G., Studitsky, V.M., and Reinberg, D. (2003). FACT facilitates transcription-dependent nucleosome alteration. Science 301, 1090-1093.
Benson, L.J., Gu, Y., Yakovleva, T., Tong, K., Barrows, C., Strack, C. L., Cook, R.G., Mizzen, C.A., and Annunziato, A.T. (2006). Modifications of $\mathrm{H} 3$ and $\mathrm{H} 4$ during chromatin replication, nucleosome assembly, and histone exchange. J Biol Chem 281, 9287-9296.

Bonne-Andrea, C., Wong, M.L., and Alberts, B.M. (1990). In vitro replication through nucleosomes without histone displacement. Nature 343, 719-726.

Brownell, J.E., Zhou, J., Ranalli, T., Kobayashi, R., Edmondson, D.G., Roth, S.Y., and Allis, C.D. (1996). Tetrahymena histone acetyltransferase A: a homolog to yeast Gcn5p linking histone acetylation to gene activation. Cell 84, 843-851.

Chuang, L.S., Ian, H.I., Koh, T.W., Ng, H.H., Xu, G., and Li, B.F. (1997). Human DNA-(cytosine-5) methyltransferase-PCNA complex as a target for p21WAF1. Science 277, 1996-2000.

Collins, N., Poot, R.A., Kukimoto, I., García-Jiménez, C., Dellaire, G., and Varga-Weisz, P.D. (2002). An ACF1-ISWI chromatin-remodeling complex is required for DNA replication through heterochromatin. Nat Genet 32, 627-632.

Cusick, M.E., Herman, T.M., DePamphilis, M.L., and Wassarman, P. M. (1981). Structure of chromatin at deoxyribonucleic acid replication forks: prenucleosomal deoxyribonucleic acid is rapidly excised from replicating simian virus 40 chromosomes by micrococcal nuclease. Biochemistry 20,6648-6658.

Cusick, M.E., DePamphilis, M.L., and Wassarman, P.M. (1984). Dispersive segregation of nucleosomes during replication of simian virus 40 chromosomes. J Mol Biol 178, 249-271.

Das, C., Lucia, M.S., Hansen, K.C., and Tyler, J.K. (2009). CBP/p300mediated acetylation of histone $\mathrm{H} 3$ on lysine 56 . Nature 459, 113-117.

Eissenberg, J.C. (2006). Divided loyalties: transdetermination and the genetics of tissue regeneration. Bioessays 28, 574-577.

Eissenberg, J.C., James, T.C., Foster-Hartnett, D.M., Hartnett, T., Ngan, V., and Elgin, S.C. (1990). Mutation in a heterochromatinspecific chromosomal protein is associated with suppression of position-effect variegation in Drosophila melanogaster. Proc Natl Acad Sci U S A 87, 9923-9927.

English, C.M., Maluf, N.K., Tripet, B., Churchill, M.E., and Tyler, J.K. (2005). ASF1 binds to a heterodimer of histones $\mathrm{H} 3$ and $\mathrm{H} 4$ : a twostep mechanism for the assembly of the $\mathrm{H} 3-\mathrm{H} 4$ heterotetramer on DNA. Biochemistry 44, 13673-13682.

Enomoto, S., and Berman, J. (1998). Chromatin assembly factor I contributes to the maintenance, but not the re-establishment, of silencing at the yeast silent mating loci. Genes Dev 12, 219-232.

Enomoto, S., McCune-Zierath, P.D., Gerami-Nejad, M., Sanders, M. A., and Berman, J. (1997). RLF2, a subunit of yeast chromatin assembly factor-I, is required for telomeric chromatin function in vivo. Genes Dev 11, 358-370.

Espada, J., Ballestar, E., Fraga, M.F., Villar-Garea, A., Juarranz, A., Stockert, J.C., Robertson, K.D., Fuks, F., and Esteller, M. (2004). Human DNA methyltransferase 1 is required for maintenance of the histone $\mathrm{H} 3$ modification pattern. J Biol Chem 279, 37175-37184.

Estève, P.O., Chin, H.G., Smallwood, A., Feehery, G.R., Gangisetty, O., Karpf, A.R., Carey, M.F., and Pradhan, S. (2006). Direct interaction between DNMT1 and G9a coordinates DNA and histone methylation during replication. Genes Dev 20, 3089-3103.

Fotedar, R., and Roberts, J.M. (1989). Multistep pathway for 
replication-dependent nucleosome assembly. Proc Natl Acad Sci U S A 86, 6459-6463.

Fowler, E., Farb, R., and El-Saidy, S. (1982). Distribution of the core histones H2A.H2B.H3 and $\mathrm{H} 4$ during cell replication. Nucleic Acids Res 10, 735-748.

Franco, A.A., Lam, W.M., Burgers, P.M., and Kaufman, P.D. (2005). Histone deposition protein Asf1 maintains DNA replisome integrity and interacts with replication factor C. Genes Dev 19, 1365-1375.

Gambus, A., Jones, R.C., Sanchez-Diaz, A., Kanemaki, M., van Deursen, F., Edmondson, R.D., and Labib, K. (2006). GINS maintains association of $\mathrm{Cdc} 45$ with $\mathrm{MCM}$ in replisome progression complexes at eukaryotic DNA replication forks. Nat Cell Biol 8 , 358-366.

Gasser, R., Koller, T., and Sogo, J.M. (1996). The stability of nucleosomes at the replication fork. J Mol Biol 258, 224-239.

Groth, A., Rocha, W., Verreault, A., and Almouzni, G. (2007). Chromatin challenges during DNA replication and repair. Cell 128, 721-733.

Groth, A., Corpet, A., Cook, A.J., Roche, D., Bartek, J., Lukas, J., and Almouzni, G. (2007). Regulation of replication fork progression through histone supply and demand. Science 318, 1928-1931.

Gruss, C., Wu, J., Koller, T., Sogo, J.M. (1993). Disruption of the nucleosomes at the replication fork. EMBO J 12, 4533-4545.

Hadorn, E. (1968). Transdetermination in cells. Sci Am 219, 110-120, passim.

Hake, S.B., and Allis, C.D. (2006). Histone H3 variants and their potential role in indexing mammalian genomes: the "H3 barcode hypothesis". Proc Natl Acad Sci U S A 103, 6428-6435.

Han, J., Zhou, H., Horazdovsky, B., Zhang, K., Xu, R.M., and Zhang, Z. (2007). Rtt109 acetylates histone H3 lysine 56 and functions in DNA replication. Science 315, 653-655.

Hansen, K.H., Bracken, A.P., Pasini, D., Dietrich, N., Gehani, S.S., Monrad, A., Rappsilber, J., Lerdrup, M., and Helin, K. (2008). A model for transmission of the H3K27me3 epigenetic mark. Nat Cell Biol 10, 1291-1300.

Henderson, D.S., Banga, S.S., Grigliatti, T.A., and Boyd, J.B. (1994). Mutagen sensitivity and suppression of position-effect variegation result from mutations in mus209, the Drosophila gene encoding PCNA. EMBO J 13, 1450-1459.

Henikoff, S., and Ahmad, K. (2005). Assembly of variant histones into chromatin. Annu Rev Cell Dev Biol 21, 133-153.

Henikoff, S., Furuyama, T., and Ahmad, K. (2004). Histone variants, nucleosome assembly and epigenetic inheritance. Trends Genet 20, 320-326.

Hertel, L., De Andrea, M., Bellomo, G., Santoro, P., Landolfo, S., and Gariglio, M. (1999). The HMG protein T160 colocalizes with DNA replication foci and is down-regulated during cell differentiation. Exp Cell Res 250, 313-328.

Hoek, M., and Stillman, B. (2003). Chromatin assembly factor 1 is essential and couples chromatin assembly to DNA replication in vivo. Proc Natl Acad Sci U S A 100, 12183-12188.

Huen, M.S., Sy, S.M., van Deursen, J.M., and Chen, J. (2008). Direct interaction between SET8 and proliferating cell nuclear antigen couples H4-K20 methylation with DNA replication. J Biol Chem 283, 11073-11077.

Jackson, V. (1987). Deposition of newly synthesized histones: new histones $\mathrm{H} 2 \mathrm{~A}$ and $\mathrm{H} 2 \mathrm{~B}$ do not deposit in the same nucleosome with new histones $\mathrm{H} 3$ and $\mathrm{H} 4$. Biochemistry 26, 2315-2325.
Jackson, V. (1990). In vivo studies on the dynamics of histone-DNA interaction: evidence for nucleosome dissolution during replication and transcription and a low level of dissolution independent of both. Biochemistry 29, 719-731.

Jackson, V., and Chalkley, R. (1985). Histone segregation on replicating chromatin. Biochemistry 24, 6930-6938.

Jasencakova, Z., Scharf, A.N., Ask, K., Corpet, A., Imhof, A., Almouzni, G., and Groth, A. (2010). Replication stress interferes with histone recycling and predeposition marking of new histones. Mol Cell 37, 736-743.

Jenuwein, T., and Allis, C.D. (2001). Translating the histone code. Science 293, 1074-1080.

Jørgensen, S., Elvers, I., Trelle, M.B., Menzel, T., Eskildsen, M., Jensen, O.N., Helleday, T., Helin, K., and Sørensen, C.S. (2007). The histone methyltransferase SET8 is required for S-phase progression. J Cell Biol 179, 1337-1345.

Kaufman, P.D., Kobayashi, R., Kessler, N., and Stillman, B. (1995). The p150 and p60 subunits of chromatin assembly factor I: a molecular link between newly synthesized histones and DNA replication. Cell 81, 1105-1114.

Kaufman, P.D., Kobayashi, R., and Stillman, B. (1997). Ultraviolet radiation sensitivity and reduction of telomeric silencing in Saccharomyces cerevisiae cells lacking chromatin assembly factor-I. Genes Dev 11, 345-357.

Kaya, H., Shibahara, K.I., Taoka, K.I., Iwabuchi, M., Stillman, B., and Araki, T. (2001). FASCIATA genes for chromatin assembly factor-1 in arabidopsis maintain the cellular organization of apical meristems. Cell 104, 131-142.

Kornberg, R.D., and Thomas, J.O. (1974). Chromatin structure; oligomers of the histones. Science 184, 865-868.

Krude, T., and Knippers, R. (1991). Transfer of nucleosomes from parental to replicated chromatin. Mol Cell Biol 11, 6257-6267.

Lachner M., O'Carroll, D., Rea, S., Mechtler, K., Jenuwein, T. (2001). Methylation of histone $\mathrm{H} 3$ lysine 9 creates a binding site for HP1 proteins. Nature 410, 116-120.

Leonhardt, H., Page, A.W., Weier, H.U., and Bestor, T.H. (1992). A targeting sequence directs DNA methyltransferase to sites of DNA replication in mammalian nuclei. Cell 71, 865-873.

LeRoy, G., Orphanides, G., Lane, W.S., and Reinberg, D. (1998). Requirement of RSF and FACT for transcription of chromatin templates in vitro. Science 282, 1900-1904.

Li, Q., Zhou, H., Wurtele, H., Davies, B., Horazdovsky, B., Verreault, A., and Zhang, Z. (2008). Acetylation of histone H3 lysine 56 regulates replication-coupled nucleosome assembly. Cell 134, 244-255.

Luger, K., Mäder, A.W., Richmond, R.K., Sargent, D.F., and Richmond, T.J. (1997). Crystal structure of the nucleosome core particle at 2.8 A resolution. Nature 389, 251-260.

Margueron, R., Justin, N., Ohno, K., Sharpe, M.L., Son, J., Drury, W.J. 3rd, Voigt, P., Martin, S.R., Taylor, W.R., De Marco, V., et al. (2009). Role of the polycomb protein EED in the propagation of repressive histone marks. Nature 461, 762-767.

Martin, C., and Zhang, Y. (2007). Mechanisms of epigenetic inheritance. Curr Opin Cell Biol 19, 266-272.

Marzluff, W.F., Wagner, E.J., and Duronio, R.J. (2008). Metabolism and regulation of canonical histone mRNAs: life without a poly $(\mathrm{A})$ tail. Nat Rev Genet 9, 843-854.

Masumoto, H., Hawke, D., Kobayashi, R., and Verreault, A. (2005). A 
role for cell-cycle-regulated histone $\mathrm{H} 3$ lysine 56 acetylation in the DNA damage response. Nature 436, 294-298.

McKnight, S.L., and Miller, O.L. Jr. (1977). Electron microscopic analysis of chromatin replication in the cellular blastoderm Drosophila melanogaster embryo. Cell 12, 795-804.

Meijsing, S.H., and Ehrenhofer-Murray, A.E. (2001). The silencing complex SAS-I links histone acetylation to the assembly of repressed chromatin by CAF-I and Asf1 in Saccharomyces cerevisiae. Genes Dev 15, 3169-3182.

Milutinovic, S., Zhuang, Q., and Szyf, M. (2002). Proliferating cell nuclear antigen associates with histone deacetylase activity, integrating DNA replication and chromatin modification. J Biol Chem 277, 20974-20978.

Moggs, J.G., Grandi, P., Quivy, J.P., Jónsson, Z.O., Hübscher, U., Becker, P.B., and Almouzni, G. (2000). A CAF-1-PCNA-mediated chromatin assembly pathway triggered by sensing DNA damage. Mol Cell Biol 20, 1206-1218.

Monson, E.K., de Bruin, D., and Zakian, V.A. (1997). The yeast Cac1 protein is required for the stable inheritance of transcriptionally repressed chromatin at telomeres. Proc Natl Acad Sci U S A 94, 13081-13086.

Mosammaparast, N., and Shi, Y. (2010). Reversal of histone methylation: biochemical and molecular mechanisms of histone demethylases. Annu Rev Biochem 79, 155-179.

Nabatiyan, A., and Krude, T. (2004). Silencing of chromatin assembly factor 1 in human cells leads to cell death and loss of chromatin assembly during DNA synthesis. Mol Cell Biol 24, 2853-2862.

Nakatani, Y., Ray-Gallet, D., Quivy, J.P., Tagami, H., and Almouzni, G. (2004). Two distinct nucleosome assembly pathways: dependent or independent of DNA synthesis promoted by histone $\mathrm{H} 3.1$ and H3.3 complexes. Cold Spring Harb Symp Quant Biol 69, 273-280.

Nakayama, J., Rice, J.C., Strahl, B.D., Allis, C.D., and Grewal, S.I. (2001). Role of histone H3 lysine 9 methylation in epigenetic control of heterochromatin assembly. Science 292, 110-113.

Natsume, R., Eitoku, M., Akai, Y., Sano, N., Horikoshi, M., and Senda, T. (2007). Structure and function of the histone chaperone CIA/ ASF1 complexed with histones $\mathrm{H} 3$ and H4. Nature 446, 338-341.

Neumann, H., Hancock, S.M., Buning, R., Routh, A., Chapman, L., Somers, J., Owen-Hughes, T., van Noort, J., Rhodes, D., and Chin, J.W. (2009). A method for genetically installing site-specific acetylation in recombinant histones defines the effects of H3 K56 acetylation. Mol Cell 36, 153-163.

Orphanides, G., LeRoy, G., Chang, C.H., Luse, D.S., and Reinberg, D. (1998). FACT, a factor that facilitates transcript elongation through nucleosomes. Cell 92, 105-116.

Papamichos-Chronakis, M., and Peterson, C.L. (2008). The Ino80 chromatin-remodeling enzyme regulates replisome function and stability. Nat Struct Mol Biol 15, 338-345.

Paul, J., and Gilmour, R.S. (1968). Organ-specific restriction of transcription in mammalian chromatin. J Mol Biol 34, 305-316.

Pesavento, J.J., Yang, H., Kelleher, N.L., and Mizzen, C.A. (2008). Certain and progressive methylation of histone $\mathrm{H} 4$ at lysine 20 during the cell cycle. Mol Cell Biol 28, 468-486.

Peters, A.H., O'Carroll, D., Scherthan, H., Mechtler, K., Sauer, S., Schöfer, C., Weipoltshammer, K., Pagani, M., Lachner, M., Kohlmaier, A., et al. (2001). Loss of the Suv39h histone methyltransferases impairs mammalian heterochromatin and genome stability. Cell, 107, 323-337.
Poot, R.A., Bozhenok, L., van den Berg, D.L., Steffensen, S., Ferreira, F., Grimaldi, M., Gilbert, N., Ferreira, J., and Varga-Weisz, P.D. (2004). The Williams syndrome transcription factor interacts with PCNA to target chromatin remodelling by ISWI to replication foci. Nat Cell Biol 6, 1236-1244.

Pospelov, V., Russev, G., Vassilev, L., and Tsanev, R. (1982). Nucleosome segregation in chromatin replicated in the presence of cycloheximide. J Mol Biol 156, 79-91.

Prior, C.P., Cantor, C.R., Johnson, E.M., and Allfrey, V.G. (1980). Incorporation of exogenous pyrene-labeled histone into Physarum chromatin: a system for studying changes in nucleosomes assembled in vivo. Cell 20, 597-608.

Probst, A.V., Dunleavy, E., and Almouzni, G. (2009). Epigenetic inheritance during the cell cycle. Nat Rev Mol Cell Biol 10, 192-206.

Randall, S.K., and Kelly, T.J. (1992). The fate of parental nucleosomes during SV40 DNA replication. J Biol Chem 267, 14259-14265.

Rea, S., Eisenhaber, F., O'Carroll, D., Strahl, B.D., Sun, Z.W., Schmid, M., Opravil, S., Mechtler, K., Ponting, C.P., Allis, C.D., et al. (2000). Regulation of chromatin structure by site-specific histone H3 methyltransferases. Nature 406, 593-599.

Recht, J., Tsubota, T., Tanny, J.C., Diaz, R.L., Berger, J.M., Zhang, X., Garcia, B.A., Shabanowitz, J., Burlingame, A.L., Hunt, D.F., et al. (2006). Histone chaperone Asf1 is required for histone H3 lysine 56 acetylation, a modification associated with $\mathrm{S}$ phase in mitosis and meiosis. Proc Natl Acad Sci U S A 103, 6988-6993.

Reese, B.E., Bachman, K.E., Baylin, S.B., and Rountree, M.R. (2003). The methyl-CpG binding protein MBD1 interacts with the p150 subunit of chromatin assembly factor 1 . Mol Cell Biol 23, 3226-3236.

Riley, D., and Weintraub, H. (1979). Conservative segregation of parental histones during replication in the presence of cycloheximide. Proc Natl Acad Sci U S A 76, 328-332.

Sarraf, S.A., and Stancheva, I. (2004). Methyl-CpG binding protein MBD1 couples histone $\mathrm{H} 3$ methylation at lysine 9 by SETDB1 to DNA replication and chromatin assembly. Mol Cell 15, 595-605.

Scharf, A.N., Barth, T.K., and Imhof, A. (2009). Establishment of histone modifications after chromatin assembly. Nucleic Acids Res 37, 5032-5040.

Schlesinger, M.B., and Formosa, T. (2000). POB3 is required for both transcription and replication in the yeast Saccharomyces cerevisiae. Genetics 155, 1593-1606.

Schotta, G., Ebert, A., Krauss, V., Fischer, A., Hoffmann, J., Rea, S., Jenuwein, T., Dorn, R., and Reuter, G. (2002). Central role of Drosophila SU(VAR)3-9 in histone H3-K9 methylation and heterochromatic gene silencing. EMBO J 21, 1121-1131.

Schulz, L.L., and Tyler, J.K. (2006). The histone chaperone ASF1 localizes to active DNA replication forks to mediate efficient DNA replication. FASEB J 20, 488-490.

Schwartz, Y.B., and Pirrotta, V. (2007). Polycomb silencing mechanisms and the management of genomic programmes. Nat Rev Genet 8, 9-22.

Seale, R.L. (1976). Studies on the mode of segregation of histone nu bodies during replication in HeLa cells. Cell 9, 423-429.

Seidman, M.M., Levine, A.J., and Weintraub, H. (1979). The asymmetric segregation of parental nucleosomes during chrosome replication. Cell 18, 439-449. 
Shahbazian, M.D., and Grunstein, M. (2007). Functions of sitespecific histone acetylation and deacetylation. Annu Rev Biochem 76, 75-100.

Shibahara, K., and Stillman, B. (1999). Replication-dependent marking of DNA by PCNA facilitates CAF-1-coupled inheritance of chromatin. Cell 96, 575-585.

Shilatifard, A. (2006). Chromatin modifications by methylation and ubiquitination: implications in the regulation of gene expression. Annu Rev Biochem 75, 243-269.

Smith, S., and Stillman, B. (1989). Purification and characterization of CAF-I, a human cell factor required for chromatin assembly during DNA replication in vitro. Cell 58, 15-25.

Sobel, R.E., Cook, R.G., Perry, C.A., Annunziato, A.T., and Allis, C.D. (1995). Conservation of deposition-related acetylation sites in newly synthesized histones $\mathrm{H} 3$ and $\mathrm{H} 4$. Proc Natl Acad Sci U S A 92, 1237-1241.

Sogo, J.M., Stahl, H., Koller, T., and Knippers, R. (1986). Structure of replicating simian virus 40 minichromosomes. The replication fork, core histone segregation and terminal structures. J Mol Biol 189, 189-204.

Sporbert, A., Gahl, A., Ankerhold, R., Leonhardt, H., and Cardoso, M. C. (2002). DNA polymerase clamp shows little turnover at established replication sites but sequential de novo assembly at adjacent origin clusters. Mol Cell 10, 1355-1365.

Stewart, M.D., Li, J., and Wong, J. (2005). Relationship between histone $\mathrm{H} 3$ lysine 9 methylation, transcription repression, and heterochromatin protein 1 recruitment. Mol Cell Biol 25, 2525-2538.

Stuwe, T., Hothorn, M., Lejeune, E., Rybin, V., Bortfeld, M., Scheffzek, K., and Ladurner, A.G. (2008). The FACT Spt16 "peptidase" domain is a histone $\mathrm{H} 3-\mathrm{H} 4$ binding module. Proc Natl Acad Sci U S A 105, 8884-8889.

Sugasawa, K., Ishimi, Y., Eki, T., Hurwitz, J., Kikuchi, A., and Hanaoka, F. (1992). Nonconservative segregation of parental nucleosomes during simian virus 40 chromosome replication in vitro. Proc Natl Acad Sci U S A 89, 1055-1059.

Taddei, A., Roche, D., Sibarita, J.B., Turner, B.M., and Almouzni, G. (1999). Duplication and maintenance of heterochromatin domains. J Cell Biol 147, 1153-1166.

Tagami, H., Ray-Gallet, D., Almouzni, G., and Nakatani, Y. (2004). Histone H3.1 and H3.3 complexes mediate nucleosome assembly pathways dependent or independent of DNA synthesis. Cell 116, 51-61.

Takami, Y., Ono, T., Fukagawa, T., Shibahara, K., and Nakayama, T.
(2007). Essential role of chromatin assembly factor-1-mediated rapid nucleosome assembly for DNA replication and cell division in vertebrate cells. Mol Biol Cell 18, 129-141.

Tan, B.C., Chien, C.T., Hirose, S., and Lee, S.C. (2006). Functional cooperation between FACT and MCM helicase facilitates initiation of chromatin DNA replication. EMBO J 25, 3975-3985.

Tsubota, T., Berndsen, C.E., Erkmann, J.A., Smith, C.L., Yang, L., Freitas, M.A., Denu, J.M., and Kaufman, P.D. (2007). Histone H3$\mathrm{K} 56$ acetylation is catalyzed by histone chaperone-dependent complexes. Mol Cell 25, 703-712.

VanDemark, A.P., Blanksma, M., Ferris, E., Heroux, A., Hill, C.P., and Formosa, T. (2006). The structure of the yFACT Pob3-M domain, its interaction with the DNA replication factor RPA, and a potential role in nucleosome deposition. Mol Cell 22, 363-374.

Verreault, A., Kaufman, P.D., Kobayashi, R., and Stillman, B. (1996). Nucleosome assembly by a complex of CAF-1 and acetylated histones H3/H4. Cell 87, 95-104.

Vincent, J.A., Kwong, T.J., and Tsukiyama, T. (2008). ATP-dependent chromatin remodeling shapes the DNA replication landscape. Nat Struct Mol Biol 15, 477-484.

Volpe, T.A., Kidner, C., Hall, I.M., Teng, G., Grewal, S.I., and Martienssen, R.A. (2002). Regulation of heterochromatic silencing and histone H3 lysine-9 methylation by RNAi. Science 297, 1833-1837.

Xie, W., Song, C., Young, N.L., Sperling, A.S., Xu, F., Sridharan, R., Conway, A.E., Garcia, B.A., Plath, K., Clark, A.T., et al. (2009). Histone h3 lysine 56 acetylation is linked to the core transcriptional network in human embryonic stem cells. Mol Cell 33, 417-427.

Xu, M., Long, C., Chen, X., Huang, C., Chen, S., and Zhu, B. (2010). Partitioning of histone $\mathrm{H} 3-\mathrm{H} 4$ tetramers during DNA replicationdependent chromatin assembly. Science 328, 94-98.

Yamasu, K., and Senshu, T. (1990). Conservative segregation of tetrameric units of $\mathrm{H} 3$ and $\mathrm{H} 4$ histones during nucleosome replication. J Biochem 107, 15-20.

Ye, X., Franco, A.A., Santos, H., Nelson, D.M., Kaufman, P.D., and Adams, P.D. (2003). Defective $S$ phase chromatin assembly causes DNA damage, activation of the $S$ phase checkpoint, and $S$ phase arrest. Mol Cell 11, 341-351.

Zee, B.M., Levin, R.S., Xu, B., LeRoy, G., Wingreen, N.S., and Garcia, B.A. (2010). In vivo residue-specific histone methylation dynamics. J Biol Chem 285, 3341-3350.

Zhang, Z., Shibahara, K., and Stillman, B. (2000). PCNA connects DNA replication to epigenetic inheritance in yeast. Nature 408 , 221-225. 